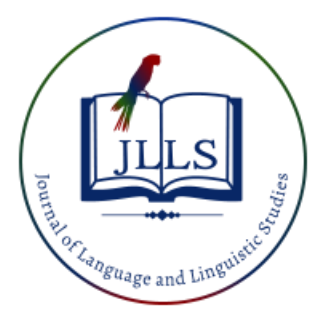

Available online at www.jlls.org

JOURNAL OF LANGUAGE

AND LINGUISTIC STUDIES

ISSN: $1305-578 \mathrm{X}$

Journal of Language and Linguistic Studies, 17(1), 56-69; 2021

\title{
The speaking difficulties of Chinese EFL learners and their motivation towards
}

\section{speaking the English language}

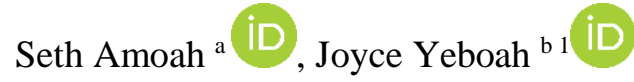 \\ ${ }^{a, b}$ Nanjing Tech University, Nanjing, China \\ APA Citation: \\ Amoah, S., \& Yeboah, J. (2021). The speaking difficulties of Chinese EFL learners and their motivation towards speaking the English \\ language. Journal of Language and Linguistic Studies, 17(1), 56-69. Doi: 10.52462/jlls.4 \\ Submission Date: 06/01/2021 \\ Acceptance Date: 15/03/2021
}

\begin{abstract}
One of the most important skills to acquire in learning a foreign language is speaking. It is however, viewed as one of the most difficult. This study involved the observation of non-English major students in the foreign language department of Nanjing Tech University. Its aim was to assess critically the factors that affect the speaking performances of Chinese EFL Learners, find out their motivational levels and explore ways to improve EFL proficiency. Two survey questionnaires, as well as an interview item, were constructed. Seventy-five respondents were conveniently sampled for the Chinese EFL learner's speaking difficulty questionnaire and, the English motivational scale, and ten out of the Seventy-five were randomly selected to respond to the interview. The factors that inhibit speaking performances were categorized as either linguistic or psychological. The outcome of the study revealed that Chinese EFL learners have speaking problems that relate more to psychological factors like anxiety, fear of mistakes, unwillingness, and fear of negative evaluation than linguistic factors such as lack of vocabulary, pronunciation, insufficient knowledge of grammar rules, reading and oral presentation.

Furthermore, the researchers investigated the motivational levels of respondents toward speaking English as motivation is considered a fundamental element in achieving oral proficiency. The findings showed that Chinese EFL learner's instrumental motivations are slightly dominant than their integrative motivation. The study recommends that instructors or teachers should create a conducive environment that will help reduce anxiety or shyness and gather adequate strategies like regular oral presentations or classroom debates to boost EFL learners' speaking confidence.
\end{abstract}

Keywords: English speaking; psychological factors; linguistic factors; motivation

\section{Introduction}

Education in the 21 st century should meet people's needs of becoming citizens of the world. In this respect, language teaching has a vital role in promoting and maintaining necessary knowledge, skills, and attitudes to eminent in the preparation of learners for interacting effectively with people of other languages and cultures (Özdemir, Pehlivan Şişman \& Büyükkarc1, 2021). More importantly, the

\footnotetext{
${ }^{1}$ Corresponding author.

E-mail address: joysyeb.jy@gmail.com
} 
demand for English oral proficiency is undoubtedly high in this rapidly changing world. The English language is spoken all around the globe and has therefore attained the status of a global language. It is also among other languages widely used in the field of education research, the internet, international relations, business, social media, travel and tourism, software, communication, entertainment, banking, etc. (Ahmed 2016). (Crystal, 2012; Rossner \& Boliho, 1990) posit that "English is an important language, as it is the most dominant international language used as an official language for a lot of countries. Most research also asserts that English is now the language most widely taught in foreign language classrooms- in more than 100 countries (Crystal, 2003; Lasanowski, 2010; Yano, 2001). It is due to these popularities and several other advantages of English that the world today is assiduously learning to attain proficiency in its respective fields, especially speaking.

Speaking English as a foreign language however is a herculean task when compared with other skills such as writing, listening, and reading. Al-Sibai (2004) depicts that the use of English as a foreign language (EFL) in oral communication is, without a doubt, one of the most common but highly complex activities and should be considered a necessary aspect when teaching the English language. Saunders, W.M., \& O'Brien (2006) state, the correct use of language form is salient for learners' oral proficiency, however, it is important to note that, learning to speak a language is not only a question of acquiring a set of rules, keeping on with a bunch of idioms and or building up a wide vocabulary. Speaking proficiency goes beyond that. Brown and Yule (1983) explained it as the skill that the student will be judged upon most in any real-life situations. It is thus, the learner's ability to communicate clearly and effectively with what has been learned.

Furthermore, contrary to other parts of the world where the popularity of English is overemphasized, Asia as a continent, and China to be precise is now getting around to accept English language learning. The English language is recently taught in schools and training centers as a foreign language. However, there is limited or inadequate practice community. The Chinese EFL Learners are therefore faced with lots of difficulties, especially with the speaking aspect. When allowing speaking, Chinese EFL learners fail to speak proficiently. The factors that affect their speaking performances are either linguistic that is of relating to vocabulary knowledge, pronunciation, or grammar and or psychological, that is anxiety, shyness or fear of mistakes and lack of motivation. It is imperative to note that, both the teacher and the learner have a role to play in the quest of improving speaking proficiency. Teachers need to support learners by motivating them. More so, learners themselves need to be motivated intrinsically.

Motivation is considered a fundamental element in achieving success in any academic field. According to Nunan (1999), motivation can be employed to easily influence learners on their hesitation toward speaking. It can therefore be concluded that motivation is a needful element in achieving speaking proficiency among Chinese EFL learners. Babu (2010) claims in his study that lack of motivation hinders learners from speaking or participating in any form of discussion in class.

With this in mind, we intended to assess speaking difficulties in the Chinese EFL learning context, trace the circumstances in which speaking difficulties are constructed as either linguistic or psychological, and the appropriate ways to motivate learners to overcome such difficulties. Aside from this as a basic aim of the current study, we attempt to contribute to research on the EFL learners' oral proficiency, speaking difficulties, and motivation and suggest frameworks or approaches to overcome speaking difficulties thereby ensuring the massive improvement of Chinese EFL learners speaking skills and oral proficiency. 


\subsection{Literature review}

In second language acquisition, one of the language skills that need to be mastered by any EFL learner is the ability to speak the target language. It is the aspect that people want to learn as fast as possible. More so, when people meet a second or foreign language learners, their first assessment is to find out if the EFL learner can speak. The other aspects come later in a conversation. Nunan (1991) explains this better when he posited that "for most people, mastering speaking skill is the single most important aspect of learning a second or foreign language, and its success is measured in terms of the ability to carry out a conversation in the language". Speaking is the delivery of language through the mouth or the action of conveying information or expressing one's feelings in speech. Florez, M.C. (1999) sees speaking as an interactive process of constructing meaning in that both its form and meaning depend on the context, the participants, their experiences, the environment, and the purpose for speaking (p.1). The EFL learner's speaking skill is therefore the ability of learners to express themselves through oral communication or language. It is an ultimate tool for communication that helps learners to express ideas, thoughts, feelings, and emotions with other people. However, for most language learners, speaking in a target language is not an easy thing to do. It requires more than a web of vocabularies, and or knowing more semantic and grammatical rules. Similarly, Zhang (2009) explains that speaking remains the most difficult skill to master for the majority of English learners, and they are still incapable of communicating orally in English. Speaking difficulty is more likely to depend on special situations and circumstances that can make one feel uncomfortable.

Moreover, whether influenced by linguistic and or psychological factors or not, it is indeed challenging for Chinese EFL learners to speak English fluently and accurately. There is a great deal of knowledge body and studies investigating the causes of speaking difficulties among learners. For example, Rabab'ah (2005) stated that several factors cause difficulties in speaking English among EFL learners. He recounted these factors as related to the learners themselves, linguistic or the teaching strategies, the curriculum, and the environment. Also, according to the study of Misbah et al (2017), the main factors that affect English language learning are the influence of first language, insufficient vocabulary, and the socio-economic status of the learner's family.

In contrast, Ur, P. (1996) argued that several factors contribute to learners speaking difficulties which may include anxiety, which comes in the form of; (I) Inhibition- Learner's worry about making mistakes, fear of criticism, or simply, (ii) having nothing to say- learners having no motivation at all to express themselves. (iii) Low participation- where one participant can talk at a time due to the nature of large classes and the probability of some learners to dominate, while others speak very little or not at all becomes high. (iv). The use of mother-tongue- here, there is the likelihood of learners who share the same native language to use it more often because it is easier and learners feel less exposed in its usage. These factors in essence are tailored toward linguistic and psychological themes.

\subsubsection{Speaking difficulties related to linguistic factors}

Linguistic competence is the ability of the language learner to use the language and its parts or forms. Language forms are linguistic factors that include aspects like grammar, pronunciation, and vocabulary. The correct use of language forms is critical for learners' oral proficiency (Saunders \& O'Brien, 2006). Compared with native speakers, it is harder for EFL learners to use accurate pronunciation, grammar, and vocabulary (Bygate, 2005). Burnkart (1998) explains that language learners need to have three areas of knowledge involved within the speaking of which mechanics of language elements (pronunciation, grammar, vocabulary) takes the first point. It emphasizes the use of the right words in the right order with the correct pronunciation. In most cases, Chinese learners of English are faced with the dilemma of when to use a word or phrase correctly in a speech and this makes them hesitant to express themselves. 


\subsubsection{Speaking difficulties related to psychological factors}

Brown (2001) attributes the root cause of student's hesitation to speak to several psychological factors such as shyness, anxiety, and fear. In the same token, Dil (2009) in the article "Turkish EFL Learners' correspondence hindrances in English language classrooms", shares the view that anxiety and unwillingness during the English speaking process are among the two greatest impediments for EFL learners speaking difficulties. According to him, anxiety and unwillingness in this regard are brought on by the apprehension of being contrarily assessed when committing errors, especially before their companions. Gebhad (2000) confirms the notion that anxiety and shyness are the main causes of complications in speaking among learners. According to Heron (2005), anxiety acts as a negative influential factor that intercepts the learner's process of mastering a skill, be it speaking in this case. It spurs up the feeling of being afraid and nervousness which usually deters the learner from achieving oral proficiency. Horwitz \& Horwitz (1986) in Zhao (2007) found out three main causes of students' anxiety; communication apprehension, test anxiety, and fear of negative evaluation.

According to them, communication apprehension is the students' ability to communicate in the target language. Students' low ability in this aspect, in many cases, causes anxious feelings among them. This apprehension tends to cause speaking problems among Chinese EFL learners. The second is test anxiety, which deals with students' fear of being tested whether through oral presentation or speaking class. The third and last cause has to do with other students' evaluations. More often than not, other students' evaluation causes anxiety among learners themselves, and the fear of being evaluated by teachers as well (Liu, 2007); Zhou et al (2004). Therefore, providing language students with creative and effective language learning environments so that they can gain communicative competence is of great importance (Ercan, 2020).

Also, researchers like Elia \& Irianti (2015) have also argued that shyness is a psychological factor that hinders learners' speaking performance. According to them, the internal meaning of shyness is portrayed by an emotion which translates to the feeling of agitation, uneasiness, or awkwardness experienced by people when doing something, engaged in a conversation, or approached by other people, especially in new environments or with people unfamiliar to them. Harmer (2007) argued that to reduce shyness and this anxiety feeling, teachers need to pay attention to each students' strengths and weaknesses so that they can create a learning method that accommodates all learners in the classroom, but more importantly, learners themselves need to be motivated by themselves or and by others. This is because motivation is long been identified as one of the major factors affecting English language teaching and learning (Gardner, 1985).

\subsubsection{Motivation}

Without a doubt, motivation has an important role to play in the success and or failure of learning a second language. Learning is a life-long process, and learners find it enjoyable and rewarding when they can develop a sustainable level of motivation necessary for long-term achievement. Motivation to learn is therefore the force that enables learners to seek out intellectual and experiential novelty. It is the force that drives and encourages learners to approach unfamiliar and often challenging circumstances with anticipation of growth and expectation to succeed. Motivation is categorized differently by different scholars; long term and short term goal (Harmer, 1991, p.3), intrinsic and extrinsic (Arnold, 2000, p.14), and integrative or instrumental motivation (Krashen, 1988, p.22).

According to Krashen (1988, p.22), some factors are related to motivation and these factors attempt to relate also to the second language learner's ability. These are integrative and instrumental factors. Integrative motivation is defined as the desire to be recognized as a part of or an important member of a community or a society that speaks a second language. It is based on interest in learning the second language sake of the need to learn about, associate, or socialize with the people who use it or because 
of the intention to participate or integrate into the second language using the same language in that community; but most times it involves emotion or affective factors a great deal (Saville-Troike, 2006, p. 86). Instrumental motivation involves the concepts of purely practical value in learning the second language to increase learners' academic achievement, career prospects, or business opportunities, giving them more prestige and influence, accessing scientific and technical information, or just passing an exam or a course of their study in school (Saville-Troike, 2006, p. 86).

Besides, learners with an instrumental motivation orientation want to learn a language because of a practical reason such as getting a job promotion or getting into university. However, learners with integrative motivation want to learn the language so that they can better understand and get to know the people who speak that language. Some people study English for both these reasons. For instance, Hedge (2000) investigated the motivation of 20 Japanese students who were studying English. The study indicated that the most common reasons for studying English as a second language were for communication with people overseas, finding employment in a high profile career, processing international information, and understanding other cultures. These research findings were related to the work of Gardner \& Lambert (1972) which confirmed that a person's need for studying a second language is for the ability to socialize with the learning language community or integrative motivation and the ability to gain knowledge applied from that learning language or instrumental motivation.

\subsection{Research questions}

The present analytical descriptive study was designed to address the following questions:

1. What factors affect the speaking performance of Chinese EFL learners?

2. What are Chinese EFL learner's levels of motivation towards speaking the English language?

3. In what ways can the Chinese EFL learner be motivated to improve English speaking proficiency?

\section{Method}

\subsection{Sample / Participants}

In this descriptive study, seventy-five non-English major students in the foreign language department of Nanjing Tech University were conveniently sampled. Out of the 75 participants, 45 were Chinese post-graduate students pursuing a non-English major. The remaining 30 participants were non-English major undergraduates. The rationale behind choosing the respondents was based on their interest and willingness to speak English although they were not obliged as in the case of students studying English as a major. Also, a total number of 10 participants out of the 75 were purposefully sampled to participate in the speaking tasks through an interview.

\subsection{Instruments}

This study attempted to address the research questions by collecting data through 3 instruments namely: Chinese EFL learner's Speaking Difficulty scale, English speaking motivational scale, and an interview session.

\subsubsection{The Chinese EFL learner's Speaking Difficulty scale}

The Chinese EFL learner's Speaking Difficulty scale was designed to assess the speaking difficulties encountered by EFL learners. The statements raised in the 30- items questionnaire were underpinned by the notion of Krashen (2003), who identified a couple of affective variables including 
motivation, anxiety, and self-confidence, and Knapp \& Hall (2006). It follows the speaking difficulties related to linguistic, psychological, and learning environments as well as L1 assistance and linguistic accuracy respectively. Moreover, to help participants assess their speaking difficulties as linguistic, the study designed question items covering variables such as limited vocabulary and pronunciation, poor knowledge of grammar rules, difficulties in constructing sentences. For psychological factors, question items were coined to be identifiable with variables such as anxiety, shyness, lack of motivation, lack of confidence, timidity, etc. Another aspect of the question items covered the respondent's native or mother tongue influence.

\subsubsection{English speaking motivational scale}

The English-speaking motivational scale is a 4-point scale adapted from the original 7-point scale format of Gardner's Attitude / Motivation Test Battery (AMI). It ranged from highly motivated to not motivated at all, unlike (Gardner, 1960) which ranged from Strongly Agree to Strongly Disagree Aspects of the questionnaire items were modified from Prapphal's Attitudes Testing (Prapphal, 1981) to gather information on respondents' motivational levels. The questionnaire had two parts in 15 items, integrative (1-7) and instrumental motivation (8-15).

\subsubsection{Interview}

After the survey, 10 respondents were randomly picked to participate in an interview. The researchers conducted this interview through Wechat video call to evaluate both the linguistic and psychological speaking difficulties encountered by Chinese EFL learners. This was to detect the problems of oral proficiency with regards to vocabulary and pronunciation, knowledge of grammar rules and anxiety levels, timidity, and fear of mistakes. The interview question was one open question that allowed respondents to speak for 5 minutes after a 3-minute preparation. We observed and recorded responses which were later vetted and transcribed by two post-graduate students.

\subsection{Data collection procedures}

Before data collection, content validation of the Chinese EFL learners speaking difficulties, English speaking motivational scale, and interview guide, were verified by consulting three academicians in the field of English Language Teaching (ELT) and a language statistician at the Linguistics department at Nanjing Tech University, who is as well an EFL teacher. After the instruments were approved we disseminated the questionnaires through an online survey platform via a WeChat link. The questionnaires were administered twice. In the initial attempt, fifty-five responses were recorded. Twenty-two participants were added after the second dissemination. In all, seventy-five respondents participated in this study, and all the responses were collated within two weeks of dissemination. Though there were two different questionnaires, the same participants responded to both and as they were instructed to answer both simultaneously with the same internet protocol address. The responses were automatically downloaded into a research folder on the survey platform. After this, 10 participants were selected at random to partake in a speaking task conducted via Wechat video call. Each participant was given 3 minutes to prepare and participants were encouraged to speak freely on a subject within 5 minutes.

\subsection{Data analysis}

For descriptive analyses of Chinese EFL learners speaking difficulties and English-speaking motivational scales, means and standard derivations and the frequencies of the responses of the Chinese EFL learners speaking difficulties and English speaking motivational scale were validated and analyzed. The reliability of the questionnaire findings was checked for internal consistency using 
Statistical Package for the Social Sciences (Version 26.0). According to Cronbach's Alpha result (.787), the internal reliability of the items $(n=15)$ was at an acceptable level. The interview section was analyzed qualitatively.

\section{Results}

\subsection{Demographic data}

This research considered three demographics variables; gender, age-range, and educational level. Table 1 presents the results obtained from the participants based on their demographics.

Table 1. Demographic Information of Participants

\begin{tabular}{llll}
\hline Demographic & Variable & Frequency & Percentage (\%) \\
\hline Gender & Male & 25 & 33.3 \\
& Female & 50 & 66.7 \\
Age range & $18-23$ years & 35 & 46.7 \\
& $24-29$ years & 40 & 53.3 \\
Educational & Undergraduates & 30 & 40 \\
level & Postgraduates & 45 & 60 \\
\hline
\end{tabular}

From Table 1, the total number of seventy-five participants responded to the questionnaires. The majority of respondents in terms of sex or gender were females, representing $66.7 \%$ whereas $33 \%$ were represented by males. It can be observed from the table that, the ages of respondents were between 18 and 29 with $53 \%$ being between age 24 and 29, 46\% also between 18 and 23. Besides, $60 \%$ of the respondents were postgraduates and $40 \%$ were undergraduates.

Table 2. Distribution of Mean and Standard deviation of Chinese EFL learner's Speaking Difficulty

\begin{tabular}{lll}
\hline Variable (N=75) & Mean & Std. Dev. \\
\hline I find it difficult for speaking English to foreign students in my English class. & 3.41 & 1.03 \\
$\begin{array}{l}\text { I find it difficult to speak English directly without much thinking of L1 whenever I } \\
\text { speak }\end{array}$ & 3.73 & 1.04 \\
I find it difficult to speak English naturally without switching to my L1 & 3.83 & 0.98 \\
It's difficult for me to be sure of myself when speaking English & 3.79 & 1.00 \\
I find it difficult whenever I speak English without hesitation & 3.84 & 0.93 \\
I find it difficult to speak English without making grammatical mistakes & 3.77 & 1.06 \\
I find it a difficult task in making English tenses correctly & 3.51 & 1.12 \\
I find it difficult believing that I am better than the other students at speaking English & 3.84 & 0.96 \\
$\begin{array}{l}\text { On saying something in English, I always find it difficult to say it directly without } \\
\text { phrasing it in Chinese, then translating it into English. }\end{array}$ & 3.81 & 0.90 \\
I find it difficult to improve my English-speaking proficiency due to fear. & 3.85 & 0.83 \\
Fluent English pronunciation is difficult for me. & 3.59 & 1.04 \\
\hline
\end{tabular}




\begin{tabular}{lll}
\hline I find it difficult when my teacher uses Chinese while explaining English lessons & 3.53 & 0.96 \\
I find it difficult when my teacher uses English while explaining English lessons. & 3.51 & 1.16 \\
I find it difficult to speak a lot of English during English lessons & 3.55 & 1.08 \\
I find it difficult to speak a lot of English outside the English classroom. & 3.85 & 1.04 \\
I do not find it difficult to speak a lot of English outside the English classroom & 3.48 & 0.99 \\
I find it difficult when I have to speak without preparation during English lessons. & 3.71 & 1.09 \\
I find it difficult to answer questions in an English classroom. & 3.57 & 1.04 \\
I find it difficult trying to explaining important issues to friends in English. & 3.61 & 0.99 \\
I find it difficult for speaking English to my teacher during English lessons. & 3.47 & 0.92 \\
I find it difficult for taking English oral exams. & 3.40 & 1.05 \\
I find it difficult for passing my English oral exams. & 3.35 & 1.11 \\
I find it difficult to even remember the words or phrases I know from the English & 3.15 & 0.97 \\
classroom. & & \\
I find it difficult debating in English in the presence of the other students during & 3.60 & 1.01 \\
English lessons. & & 0.96 \\
I find it difficult speaking to native English speakers. & 3.47 & 1.11 \\
I find it difficult to understand every word the teacher says in the English classroom. & 3.43 & 3.68 \\
I find it difficult to voluntarily answer questions during English lessons. & 3.60 & 1.03 \\
I find it difficult to narrate or describe events orderly in English & 3.68 & 0.98 \\
I find it difficult to present my academic research in English during oral presentations & 3.65 & 0.99 \\
Most times, it takes longer to defend myself effortlessly in English when arguing with \\
my friends & 3.65 & \\
\hline
\end{tabular}

In an attempt to answer the first research question;' what factors affect the speaking performance of Chinese EFL learners?' a Chinese EFL learner's Speaking Difficulty scale was designed. Looking closely at table 2, the 30 -items question showed that, the participants had difficulties in speaking. With 5 as the maximum level of difficulty and 1 as the minimum, table 2 shows that the study participants' responses were more than average for all questions with means more than 2.50 which is in this case considered average. The statements with the highest means were recorded for items "I find it difficult to improve my English-speaking proficiency due to fear", "I find it difficult to speak a lot of English outside English classroom", "I find it difficult whenever I speak English without hesitation" and "I find it difficult believing that I am better than the other students at speaking English" with means of 3.85, 3.85, 3.84 and 3.84 respectively. These statements are items listed as psychological factors that cause speaking difficulties. The statement "I find it difficult to even remember the words or phrases I know from English classroom" had the lowest mean of 3.15. This item is categorized under linguistic factors that are lack of vocabulary.

This result from the Chinese EFL learner's Speaking Difficulty scale was discussed in tandem with our observation of the semi-structured interview of 10 respondents. The interview question was an open question that allowed participants to speak freely. The speaking difficulties encountered by Chinese EFL learners were recorded and the researchers based the results on two factors; linguistic and psychological. 


\subsection{The results from interview questions}

\subsubsection{Linguistic factors}

The linguistic problems encountered by Chinese EFL learners were vocabulary and pronunciation, grammar, and oral presentation. The open question "Some people think that the secret of success is happiness, what do you think?" allowed participants to speak while we observed. From an interview, we realized that their answers were basically in line with the responses analyzed from the speaking difficulty questionnaire. For instance, the statements "I find it difficult to speak English without making grammatical mistakes" and "I find it a difficult task in making English tenses correctly". Out of the 10 participants, we noticed that 5 interviewees had grammatical problems that are a problem that has to do mildly was grammar rule. For example, interviewees 2, 4, 5, 8, and 9 had problems with concord and tenses in the construction of sentences. Interviewee 2 made a statement, "happiness isn't about a good job and it does not matter if you have a family" instead of perhaps saying "happiness isn't about a good job and what matters is if you have a loving family".

\subsubsection{Psychological factors}

To detect the problems that cause speaking difficulties among respondents with regards to their anxiety levels, timidity, and fear of mistakes. We observed that the psychological factors which the researchers classified under speaking anxiety, timidity, and fear of mistakes were the most difficult problems faced by participants. This indicates a low level of speaking confidence and self-efficacy. Most interviewees started the conversation by saying "don't mind my English", "my English is bad" and or "forgive my poor English" (interviewee 1, 3, 4, 6, 7, 8, 9, and 10) being more than half of the participants. There were obvious hesitations in answering the question and the disposition and mannerisms observed by the researchers were low self-confidence, fear of being evaluated negatively, high levels of anxiety, and mostly the fear of making a mistake during the speech hence the obvious hesitations. These findings also correspond to results from the speaking difficulty scale, for instance, the statement "I find it difficult to voluntarily answer questions during English lessons" which without a doubt is a result of these psychological factors raised.

\subsection{English speaking motivational scale}

This section of the study attempts to answer the second research question; 'what are Chinese EFL learners' speaking motivations toward speaking the English Language?' The table below shows the detail of the study result. 15 items have been categorized under instrumental (7) and integrative motivation (8) with their corresponding means and standard deviation.

Table 3. Results of Integrative Motivational Orientation Factors

\begin{tabular}{lllll}
\hline Category & Motivation Factor (N=75) & Mean & Std. Dev & $\begin{array}{l}\text { Rating of motivational } \\
\text { level }\end{array}$ \\
\hline & $\begin{array}{l}\text { I push myself to speak English when I meet } \\
\text { foreign friends. }\end{array}$ & 2.67 & 1.07 & Fairly motivated \\
& $\begin{array}{l}\text { I set time aside in a day to learn oral } \\
\text { English without supervision. }\end{array}$ & 1.00 & Fairly motivated \\
& $\begin{array}{l}\text { I push myself to speak as much English as } \\
\text { possible to enjoy English movies, literature, }\end{array}$ & & Fairly motivated \\
pop music, etc. & & & \\
& I push myself to speak more English than & 2.21 & .98 & Fairly motivated \\
\hline
\end{tabular}


the Chinese language in the day.

I push myself to speak English even after

2.44

Fairly motivated

the English lesson because I am interested in it.

I set time in a day speaking English to

Fairly motivated appreciate the life of native speakers.

I pay extra attention to my teacher during

English lessons because English speaking is important to me

Table 3 reveals that respondents have fair levels of integrative motivation. This is clear in that the means of integrative motivation factors of the respondents range from 2.19 to 2.67. The statement "I pay extra attention to my teacher during English lessons because English speaking is important to me", "I set time aside in a day to learn oral English without supervision" and "I push myself to speak English when I meet foreign friends" have the highest means with 2.69 and 2.67 respectively.

The statement "I push myself to speak as much English as possible to enjoy English movies, literature, pop music, etc." and "I push myself to speak English even after English lessons because I am interested in it" had mean scores of 2.55 and 2.44. The lowest mean of 2.21 and 2.19 are statements, "I push myself to speak much more English than the Chinese language in the day" and "I set time in a day speaking English to appreciate the life of native speakers". However, in all, it can be said that all the mean scores show respondents are fairly motivated.

Table 4. Results of instrumental motivational orientation factors

\begin{tabular}{|c|c|c|c|c|}
\hline Category & Motivation Factor $(\mathrm{N}=75)$ & Mean & Std. Dev. & $\begin{array}{l}\text { Rating of } \\
\text { motivational level }\end{array}$ \\
\hline \multirow{8}{*}{ 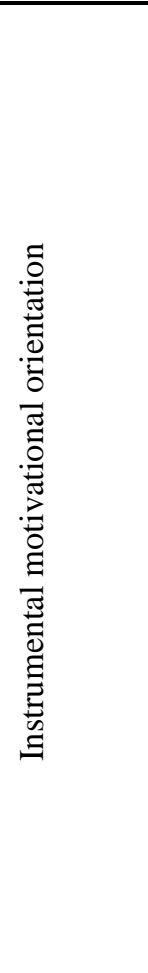 } & $\begin{array}{l}\text { I push myself to speak English to express my } \\
\text { thoughts during English lessons. }\end{array}$ & 2.67 & .92 & Fairly motivated \\
\hline & $\begin{array}{l}\text { I push myself to speak English to confidently } \\
\text { speak to my teachers and colleagues. }\end{array}$ & 2.63 & .93 & Fairly motivated \\
\hline & $\begin{array}{l}\text { I set time in a day to learn oral English to pass my } \\
\text { English oral test or exam. }\end{array}$ & 2.84 & .93 & Fairly motivated \\
\hline & $\begin{array}{l}\text { I push myself to speak English to join the English } \\
\text { debating society and other English groups on } \\
\text { campus. }\end{array}$ & 2.36 & 1.05 & Fairly motivated \\
\hline & $\begin{array}{l}\text { I push myself to speak English to impress people } \\
\text { for job or career prospects. }\end{array}$ & 2.69 & .92 & Fairly motivated \\
\hline & $\begin{array}{l}\text { I push myself to speak English to present my } \\
\text { academic research in English during oral } \\
\text { presentations. }\end{array}$ & 2.92 & .82 & Fairly motivated \\
\hline & $\begin{array}{l}\text { I push myself to speak English to impress my } \\
\text { teachers. }\end{array}$ & 2.49 & 1.02 & Fairly motivated \\
\hline & $\begin{array}{l}\text { I push myself to speak English to be seen as well } \\
\text { educated. }\end{array}$ & 2.57 & .95 & Fairly motivated \\
\hline
\end{tabular}


Table 4 shows the mean score of the instrumental motivation of the respondents with the highest mean scores of 2.92 and 2.84, being the statements "I push myself to speak English to present my academic research in English during the oral presentation" and "I set time in a day to learn oral English to pass my English oral text or exams" respectively. The statements "I push myself to speak English to impress other people for job or career prospects" and "I push myself to speak English to express my thoughts during English lessons" had relatively average means of 2.69 and 2.67. Even though all the means of instrumental motivation suggest respondents are fairly motivated, the statements "I push myself to speak English to impress my teachers" and "I push myself to speak English to join the English debating society and other English groups on campus" had the lowest mean of 2.49 and 2.36.

\section{Discussion}

The outcome of the survey revealed that the factors affecting the speaking performances of Chinese EFL learners are more psychological than linguistic. This result answers the question of what factors affect the speaking performance of Chinese EFL learners. It agrees with the research finding of Dil, Y. (2009) who posits that anxiety and unwillingness are factors that cause speaking difficulties among Turkish EFL learners. It agrees also with the findings of Ur, P. (1996) who argued that several factors contribute to learners speaking difficulty. Ur listed anxiety, which comes in the form of inhibition, that is learners' worry about making mistakes, fear of criticism, or simply having nothing to say as a major factor that inhibits learners speaking performances.

From the interview sessions, the researchers observed all the interviewees had a solid vocabulary although their Chinese accent one way or the other influenced their pronunciation. Concerning their oral presentations, they lacked consistence and coherence. Students speaking problems should therefore not be attributed only to psychological factors.

The overall motivational levels of Chinese EFL learners toward speaking the English language were significantly fair. Chinese EFL learners are fairly motivated to speak English for numerous reasons thus revealing Chinese EFL learner's inclination toward instrumental motivation as much as an integrative motivation. Both table $3 \& 4$ answers the question of what Chinese EFL learner's levels of motivation towards speaking the English language are. Respondents are fairly motivated to speak English, that is either integrative or instrumentally though they are slightly more instrumentally motivated. This result is congruent with Hedge, T. (2000), who investigated the motivation of 20 Japanese students who were studying English. His findings posited that the most common reasons for studying English as a second language were for communication with people overseas, finding employment in a high profile career, processing international information, and understanding other cultures.

The findings also contradict with the works of Gardner, R. C. (2001) who believes that integrative motivation is the most dominant form of motivation. Gardner, R. C., \& Lambert, W. E. (1972) suggested that a person's need for studying a second language is for the ability to socialize with the learning language community or integrative motivation and the ability to gain knowledge applied from that learning language or instrumental motivation.

\section{Conclusions}

The current study was conducted to critically access "Chinese EFL Learners' speaking difficulties, motivation, and oral proficiency. Speaking difficulties are universal among people and Chinese EFL learners are no exceptions. The Chinese EFL learner, however, is confronted with a lot of problems that negatively affect mastering English skills and these problems happens to be more psychological than it is linguistic. They are however also fairly motivated with slight dominance in instrumental 
motivation. These findings have relevant implications and should lead to recommendations for future studies.

Based on the findings from the research, the researchers came out with the following recommendations;

1. Instructors or teachers should help create a conducive environment that will help reduce the feeling of anxiety or shyness. Teachers need to pay attention to each student's strengths and weaknesses to create a learning method that accommodates all learners in the classroom.

2. Instructors or teachers should gather adequate strategies such as regular oral presentations or classroom debates to boost EFL learner's speaking confidence. It will motivate EFL learners to set aside time in a day to speak English, even outside English lessons. This will help them overcome anxiety, the fear of making mistakes, and or criticisms by teachers or other students.

3. By critically observing learners and giving mindful feedbacks, instructors will encourage learners to speak without fear or shame.

4. EFL learners should be encouraged to join English debating clubs or societies. Again, they motivate themselves by getting in touch with English speakers, watching native English movies, news, documentary, Ted talks, etc., to create a desirable environment that will ensure English oral proficiency.

5. The focus of teachers on mitigating the inhibitions in speaking should not only be on the psychological factors. Learners must be encouraged to spend time on reading literature, learning grammar, pronunciation, and on vocabulary as well.

\section{Acknowledgments}

This paper is based on the MA Thesis of the first author.

\section{References}

Al-Sibai, D. (2004). Promoting Oral fluency of Second Language Learners: Educational Linguistics. Department of English. King Saud University.

Arnold, J. (2000). Affect in language learning. Cambridge: Cambridge University Press.

Babu, R. (2010). Teaching Spoken English for Non-native Students: Problems, Solutions and techniques. [Online] Available: http://www.eltweekly.com/elt-newsletter/2010/06/60-articleteaching-spoken-English-for-non-native-students-problems-solutions-and-techniques-by-a-rameshbabu/. (March 15, 2011)

Brown, G., \& Yule, G. (1983). Teaching the spoken language. Cambridge: Cambridge University Press. Google Scholar

Brown, H.D. (2001). Teaching by Principles. An Interactive Approach to Language Pedagogy, Englewood Cliffs: Prentice-Hall.

Burnkart, G.S. (1998). Spoken language: What it is and how to teach it. Retrieved on November 19, 2020 from: http://www.nclrc.org/essentials/speaking/goalsspeak.htm.

Bygate, M. (2005). Oral second language abilities as expertise. In K. Johnson (Ed.), Expertise in Second Language Learning and Teaching (pp. 104-127). Baisingstoke: Palgrave MacMillan.

Crystal, D. (2012). English as a Global Language. Cambridge, UK: Cambridge University Press. 
Crystal, D. (2003). English as a Global Language. Cambridge, UK: Cambridge University Press.

Dil, Y. (2009). EFL Learners' communication obstacles. Electronic Journal of Social Sciences, 8(29), 84-100. ISSN1304-0278.

Elia, F., \& Irianti, D. (2015). Psychological Factors that Hinder Students from Speaking in English. $J$ SHMIC, 2(4).

Ercan, B. (2020). Language preparatory school students' use of modern technologies to study English. Journal of Language and Linguistic Studies, 16(3), 1402-1414. Doi: 10.17263/jlls.803824.

Florez, M. C. (1999). Improving adult English language learners' speaking skills. The CAELA Guide For Adult ESL Trainers, 16-20.

Gardner, R. C., \& Lambert, W.E. (1972). Attitude and Motivation in Second Language Learning. Rowley, MA: Newbury House.

Gardner, R.C. (1985). Social psychology and second language learning: The role of attitudes and Motivation. London: Edward Arnold Publishers.

Gebhard, G.J. (2000). Teaching English as a Foreign or Second Language. USA: The University of Michigan Press.

Harmer, J. (1991). The practice of English language teaching. London: Longman.

Hedge, T. (2000). Teaching and learning in the language classroom. Oxford: United Kingdom: Oxford University Press

Heron, T. (2005). Shyness \& Social Anxiety. Newcastle: North Tyneside and Northumberland Jennifer M. Bonds-Raacke \& John D. Raacke, 2014. Retrieved on November 19, 2020 from: https://he.kendallhunt.com/sites/default/.../Bonds_Raacke_Research_2e_Ch4.pdf.

Horwitz, E. K., \& Horwitz, M. B. (1986). Foreign Language Classroom Anxiety. Joann Cope Source: The Modern Language Journal, 70(2) (Summer, 1986), pp. 125-130

Knapp, M., \& Hall, J. (2006). Nonverbal communication in human interaction. Belmont, CA: Thomson Wadsworth.

Krashen, S. (2003). Explorations in language acquisition and use: The Taipei lectures. Portsmouth, NH: Heinemann.

Krashen, S. (1988). Second language acquisition and second language learning. London: PrenticeHall International (UK).

Lasanowski, V. (2010). Can speak, will travel: The influence of language on global students' mobility. In R. Bhandari \& P. Blumenthal (Eds.), International students and global mobility in higher education: National trends and new directions (pp. 192-209). New York, NY: Palgrave Macmillan.

Liu, M. (2007). Anxiety in Oral English Classrooms: A Case Study in China. Column 3/Number 1 May 2007. pp. 119-121.

Misbah, N., Mohamad, M., Yunus, M. and Ya'acob, A. (2017). Identifying the Factors Contributing to Students' Difficulties in the English Language Learning. Creative Education, 8, 1999-2008. DOI: 10.4236/ce.2017.813136

Nunan, D. 1991. Language Teaching Methodology. A Textbook for Teachers. New York: PrenticeHall International, Ltd.

Nunan, D. (1999). Second Language Teaching and Learning. Boston: Heinle Publishers. 
Özdemir, A., \& Pehlivan Şişman, E., \& Büyükkarc1, K. (2021). Pluralistic approaches to languages and cultures: a scale development study. Journal of Language and Linguistic Studies, 17(Special Issue 2), 848-865.

Prapphal, K. (1981). Learning English in Thailand: Affective, demographic and cognitive factors. Unpublished doctoral dissertation, University of New Mexico.

Rabab'ah, G. (2003). Learning communication problems facing Arab learners of English: A personal Perspective. TEFL Web Journal, 2(1), 63-75.

Rossner, R., \& Boliho, R. (1990). Currents of change in English language teaching ( ${ }^{\text {nd }}$ Ed). NY: Oxford University Press.

Saunders, W. M., \& O'Brien. (2006). Oral language. In F. Genesee, K. Lindholm-Leary, W. M. Saunders, \& D. Christian (Eds.), Educating the English Language Learners: A Synthesis of Research Evidence (pp. 14-45). Cambridge: Cambridge University Press.

Saville-Troike, M. (2006). Introducing second language acquisition. New York: Cambridge University Press.

Ur, P. (1996). A course in Language Teaching. Practice and Theory. Cambridge: Cambridge University Press.

Yano, Y. (2001). World Englishes in 2000 and beyond. World Englishes, 20(2), 119-131.

Zhang, S. (2009). The role of input, interaction, and output in the development of oral fluency. English Language Teaching, 2(4), 91-100.

Zhao Na. (2007). A Study of High School Students' English Learning Anxiety. The Asian EFL Journal Quarterly, 9(3).

Zhou, N. et al. (2004). How English As A Second Language Affects Chinese Students Giving Presentations During Class In U.S. A, Thesis Proposal. Graduate School of Marietta College.

\section{AUTHOR BIODATA}

Amoah Seth holds a Bachelor of Arts (Twi Education) from the University of Education, Winneba Ghana. Currently, he is a final year post graduate student at the Nanjing Tech University China, pursuing a three-year Master of Arts degree in Foreign Languages and Applied Linguistics, and he is to graduate in June 2021. His research interest is in Second Language Acquisition, Language Teaching, and General Linguistics.

Yeboah Joyce graduated from the University for Development Studies in Ghana. She has a Bachelor's degree in Development Education Studies. She joined the Nanjing Tech University in the year 2018 for a 3 year master's degree in Foreign Languages and Applied Linguistics. With her being interested in Second language Acquisition, she carries research mainly on Language Learning Strategies, Chinese EFL Learners' speaking difficulties, and EFL proficiency. 